\title{
RAMÓN MARÍA DEL VALLE INCLÁN, EL HIJO PRÓDIGO DE LA GENERACIÓN DEL 98
}

Jaime Castañeda Iturbide*

RESUMEN: Un recuerdo del gran escritor y personaje, don Ramón del Valle Inclán: su personalidad estrafalaria y consistente; su pertenencia -y amistad-a la Generación del 98, y la creación estética del esperpento, que se refleja en sus obras, particularmente en las más famosas, Luces de Bohemia y Tirano Banderas.

\section{yose}

ABSTRACT: This article is dedicated to the memory of the great writer and protagonist, Don Ramón del Valle Inclán. We pay tribute to his outlandish yet consistent personality, his association and friendship with the Generation of '98, and the creation of the esperpento, present in his works, notably in the most famous ones, Luces de Bohemia and Tirano Banderas.

PALABRAS ClAVE: Generación del 98, Valle Inclán, esperpento, México, Luces de Bohemia, Tirano Banderas.

KEY WORDS: Generation of '98, Valle Inclán, esperpento, Mexico, Luces de Bohemia,

Tirano Banderas.

RECEPCIÓN: 04 de abril del 2011.

APROBACIÓN: 11 de ocutbre del 2011.

*Universidad Marista. 
La reproducción total o parcial de este artículo se podrá hacer si el ITAM otorga la autorización previamente por escrito. 


\section{RAMÓN MARÍA DEL VALLE INCLÁN, EL HIJO PRÓDIGO DE LA GENERACIÓN DEL 98}

$U_{\text {na de las etapas más brillantes de }}$ la literatura española es, sin duda, la que corresponde al surgimiento, consolidación y ocaso de la llamada Generación del 98. Ésta significó el inicio de una profunda renovación, que habría de verificarse en el ámbito de las letras y el pensamiento hispánicos, desde los últimos años del siglo XIX hasta la primera mitad del siglo XX.

Por ello, no resulta exagerado afirmar que la Generación del 98 sacudió a toda España con la fuerza de su acento crítico y la belleza trágica de su inspiración. La prueba fehaciente de esta singular relevancia se refleja todavía en nuestros días, en cursos universitarios, seminarios, conferencias y artículos periodísticos polémicos que continúan suscitando las obras de quienes encabezaron dicha generación.

Mientras España perdía sus últimas colonias en América (Filipinas, Puerto Rico y Cuba), un grupo de jóvenes escritores se lanzaban a la lucha por la regeneración de su patria. Atrás quedaban los tiempos heroicos del Gran imperio español, el más extenso y poderoso de cuantos han existido sobre la tierra, y llegaba la hora de hacer frente -con valentía y humildad-a las nuevas circunstancias impuestas por la historia.

¿Quiénes fueron los integrantes de tan extraordinaria generación de poetas, ensayistas, dramaturgos y narradores? Los estudiosos del tema no acaban de ponerse de acuerdo, $y$, a decir verdad, nunca llegarán a un entendimiento definitivo, cuestión que finalmente no es tan 
importante. A nuestro juicio y después de muchas consultas y lecturas, formaron parte de esta generación: Pío Baroja, José Martínez Ruíz “Azorín”, Ramiro de Maeztu (a quienes se denominó inicialmente "el Grupo de los tres”), Miguel de Unamuno, Antonio Machado y Ramón del Valle Inclán. ${ }^{1}$

En el año de 1898 tuvo lugar la guerra entre España y los Estados Unidos, que culminó con la derrota de la nación europea y, consecuentemente, la pérdida de Cuba. Precisamente en ese mismo año, se dieron a conocer o reafirmaron su prestigio los integrantes de la generación, quienes, por otra parte, publicaron artículos, en periódicos y revistas, cuyo contenido hacía alusión al desastre ocurrido en tal fecha, misma que se convirtió en un símbolo de doble significación: la liquidación de una España imperial y el nacimiento de una España nueva, proyectada hacia el futuro. Los miembros de la Generación del 98 mantuvieron, al menos al principio, una cierta amistad, no exenta de frecuentes discusiones y altercados, dada la recia personalidad de cada uno de ellos.

Existen varios estudios que analizan las condiciones que deben manifestarse para que un grupo de escritores o artistas en general, pueda considerarse una auténtica generación, historiográficamente hablando. En el caso de la del 98 lo indiscutible es que comparten muchas ideas en común: ${ }^{2}$

1. Distinguieron la España real y la España oficial, falsa y aparente. Su preocupación por la identidad de lo español está en el origen del llamado debate sobre el "ser de España", que continuó aún en las siguientes generaciones.

2. Siendo originarios de diferentes regiones geográficas de España, sienten un gran interés y amor por Castilla; revalorizan su paisaje y sus tradiciones, su lenguaje castizo y espontáneo, sus mitos literarios $\mathrm{y}$ tradiciones.

3. Rompen y renuevan los moldes clásicos de los géneros literarios, creando nuevas formas en todos ellos, En la narrativa, la nivola unamu-

${ }^{1}$ Cfr. Armando Urbideti, Narradores del 98, 1981, México, Editorial Arión, p. 7.

${ }^{2}$ Cfr. Pedro Salinas, Literatura Española del Siglo XX, 1972, Madrid, Alianza Editorial, pp. $75-83$. 
niana; la novela impresionista y lírica de Azorín, que experimenta con el espacio y el tiempo y hace vivir al personaje en varias épocas; la novela abierta y disgregada de Baroja, influida por el folletín; o la novela casi teatral y cinematográfica de Valle Inclán. En el teatro, el esperpento y el expresionismo del propio Valle Inclán o los dramas filosóficos de Unamuno.

4. Rechazan la estética del Realismo y su estilo de frase amplia, de elaboración retórica y de carácter detallista, prefiriendo un lenguaje más cercano a la lengua popular, de sintaxis más corta y formato impresionista.

5. Intentaron introducir en España las corrientes filosóficas del irracionalismo europeo, en particular de Niestzsche (Azorín, Maeztu, Baroja, Unamuno), de Schopenhauer (especialmente Baroja), de Kierkegaard (Unamuno) y de Henri Bergson (Machado).

6. Coinciden en el pesimismo, la actitud crítica y rebelde, el individualismo y egocentrismo, en esto último particularmente Unamuno y Valle Inclán.

7. Ideológicamente comparten las tesis del Regeneracionismo, que ilustran de forma artística y subjetiva.

Todos y cada uno de los miembros de esta generación llegaron a destacar no sólo en España, sino en el mundo entero. Un rasgo muy especial que distingue a los noventayochistas de otros grupos o movimientos literarios es que cultivaron prácticamente todas las modalidades o géneros de la literatura: novela, cuento, ensayo, crónica, artículo periodístico, teatro y poesía. Claro está que a cada quien se le facilitó más éste o aquél por encima de los demás, aunque no por ello dejasen de dominarlos todos.

Otra de las características peculiares de los miembros de esta generación -si no de todos, sí de la mayoría-, fue su asidua participación en las tertulias madrileñas, donde se reunían personajes destacados del mundo del arte y la cultura, así como jóvenes aspirantes a la fama, deseosos de escuchar a los grandes maestros. Las tertulias, realizadas en innumerables cafés madrileños, eran magníficos escenarios de la vida bohemia de aquella época. Por ahí desfilaron, además de los noventayochistas, Villaespesa, Benavente, Rubén Darío, Ricardo Baroja, Gómez de la Serna, Manuel Machado, por nombrar sólo a algunos de los más famosos. 
Asimismo, los autores del 98 se agruparon en torno a algunas revistas literarias: Don Quijote (1892-1902), Los Helechos (1894-1895), Germinal (1897-1899), Vida Nueva (1898-1900), Revista Nueva (1899), Plenitud (1901-1902), Electra (1901), Helios (1903-1904) y Alma Española (1903-1905), entre otras.

Pues bien, el más independiente, excéntrico, insolente y demás adjetivos similares, de los escritores de la Generación del 98, fue sin lugar a dudas, Ramón María del Valle Inclán. También es el más representativo del grupo, no obstante que en varias ocasiones negara pertenecer a dicha generación. Hacemos a continuación algunos comentarios a su vida y obra, ahora que conmemoramos 75 años de su muerte.

Valle Inclán nació en 1866 en Villanueva de Arosa, pueblo de pescadores y campesinos de la provincia de Pontevedra, en Galicia. Fue el segundo hijo del marinero y escritor Ramón del Valle Bermúdez y de Dolores de la Peña y Montenegro, ambos de ascendencia hidalga, poseedores de títulos nobiliarios y viejos fueros, pero venidos a menos. Fue bautizado con tres nombres: Ramón José Simón, con los apellidos Valle y Peña. Adoptaría después el apellido de uno de sus antepasados paternos, Francisco del Valle Inclán, abandonando el materno. El nombre de Ramón se le puso en honor a su padre, el de José por ser

84 el patrono de la madrina y abuela materna del bautizado, y Simón por ser el santo del día en que nació. Finalmente, el nombre que utilizó como escritor, que todos conocemos, fue Ramón María del Valle Inclán.

Dispuso desde su primera infancia de la buena biblioteca paterna y se le asignó un preceptor con el que estudió gramática latina. Posteriormente, ingresó a un Instituto de segunda enseñanza en Pontevedra y, siguiendo la imposición directa de su padre, se matriculó en la Universidad de Santiago para estudiar derecho. Como era de suponer, frecuentaba más los cafés que las aulas, o se pasaba tardes enteras en la biblioteca de la Universidad. La visita de Zorrilla a Santiago de Compostela para dar una conferencia en la Universidad le produce una honda impresión y queda seducido por la personalidad del autor del Tenorio. Con la muerte de su padre, abandonó la carrera de derecho por la que no sentía ningún interés y regresó a Pontevedra, donde impartió clases particulares de latín por unos meses. Aunque la herencia del padre 
no era de mucha cuantía, decide viajar a Madrid y comenzar una nueva vida.

A partir de su llegada a la capital española su vida adquirió proporciones de leyenda en una sucesión interminable de truculentas anécdotas -inventadas unas, verídicas otras-, cuyo variado repertorio conforma el mejor esperpento de cuantos escribiera tan formidable esteticista.

No es la intención continuar con una detallada reseña biográfica del escritor gallego, basten el conocimiento de su origen, la explicación de su nombre y ciertos datos sobre los primeros años de su vida para entender parte de su compleja personalidad. Para algún lector interesado en una biografía completa de Valle Inclán, recomendamos ampliamente la escrita por otro Ramón, Gómez de la Serna³ (1888-1963), extraordinario escritor madrileño, que conoció profundamente a Don Ramón -así lo llamaba- desde la tertulia en el Café de Levante hasta su muerte acaecida el 5 de enero de 1936, poco antes de que estallara la Guerra civil española.

Durante los dos primeros años de su estancia en Madrid, Valle Inclán empieza a destacar más por su ingenio y personalidad excéntrica, manifiestos en las tertulias de los numerosos cafés que frecuentaba, como por su presencia asidua y escandalosa en los teatros madrileños, que por sus primeros cuentos y artículos publicados en los periódicos El Globo y la Ilustración Ibérica.

Las primeras obras literarias de Valle Inclán lo ubican totalmente en la corriente modernista, mostrando su extraordinaria condición, tanto en la prosa como en el diálogo, no así en el verso donde aparece limitado y convencional. "Valle Inclán es ante todo un escritor modernista, pero no un modernista cualquiera, sino el intérprete más calificado entre nosotros del modernismo en la prosa narrativa". ${ }^{4}$

Precisamente, la obra más reconocida de su primera etapa son las Sonatas. Se trata de cuatro novelas: Sonata de otoño (1902); Sonata de estio (1903); Sonata de primavera (1904), y Sonata de invierno (1905). En conjunto son una serie de narraciones exóticas, redactadas con un

${ }^{3}$ Ramón Gómez de la Serna, Don Ramón María del Valle Inclán, 1959³, Madrid, Espasa Calpe, Colección Austral.

${ }^{4}$ Emiliano Diez-Echarri y José Ma. Roca Franqueza, Historia de la Literatura Española e Hispanoamericana, 1972, Madrid, Aguilar, p. 1370. 
lenguaje esmeradamente trabajado, que incluyen algunos elementos autobiográficos. Esta obra marca un cambio de clima tan radical en la prosa narrativa española como el que se dio en el campo de la poesía con la publicación de Azul y Prosas profanas, de Rubén Darío.

Las Sonatas llevan por subtítulo Memorias del Marqués de Bradomín, un tipo donjuanesco, cínico y sensual, al que Valle Inclán hace hablar en primera persona para distraernos con el relato de sus fantásticas aventuras. El propio autor nos presenta a Bradomín como un don Juan "feo, católico y sentimental", tres características que no coinciden precisamente con el concepto que tenemos, ni del Burlador creado por Tirso de Molina, ni del don Juan ideado por Zorrilla; pero sí representa al gran seductor, al indómito aventurero, al conquistador de amores imposibles.

Frente a este tipo masculino único, Valle Inclán presenta cuatro tipos de mujer en consonancia con las cuatro estaciones del año; asimismo, la acción se desarrolla en cuatro épocas y escenarios distintos. Si bien el marqués de Bradomín tiene mucho del propio Valle Inclán -origen noble, estancia en Italia, viaje a México, amores apasionados, perdió un brazo y tuvo un final doloroso-, no se puede afirmar que sea una obra autobiográfica. Es cierto, por otro lado, que la personalidad de Valle Inclán era muy singular (teatral, esperpéntica, insólita) y que en buena medida está reflejada en su extensa obra.

Ramón Gómez de la Serna lo describe así: "Era la mejor máscara a pie que cruzaba la calle de Alcalá". "Eximio escritor y extravagante ciudadano" lo llamó con acierto Primo de Rivera. "Su silueta estrafalaria y casi grotesca atraía la atención de los transeúntes. Su conversación maledicente y aguda llenó durante muchos años el recinto de varios cafés madrileños", comenta Francisco Madrid. ${ }^{5}$ Rubén Darío, su gran amigo y compañero de tertulias, le dedicó estos versos:

Este gran don Ramón de las barbas de chivo, cuya sonrisa es la flor de su figura, parece un dios altanero y esquivo que se animase en la frialdad de su escultura.

${ }^{5}$ Francisco Madrid, La vida altiva de Valle Inclán, 1943, Buenos Aires, Poseidón, p. 54. 
Este gran don Ramón del Valle Inclán me inquieta, a través del zodiaco de sus versos actuales se me esfuma en radiosas visiones de poeta o se me rompe en un fracaso de cristales. Yo le he visto arrancarse del pecho la saeta que le lanzan los siete pecados capitales. ${ }^{6}$

El mismo Valle Inclán intentó retratarse y lo hizo con la exuberante imaginación que ponía en todas sus cosas: "Este que veis aquí de rostro español y quevedesco, de negra quedeja y luenga barba, soy yo: don Ramón del Valle Inclán. Estuvo el comienzo de mi vida lleno de azares. Fui hermano converso en un monasterio de cartujos y soldado en tierra de Nueva España. Una vida como la de aquellos segundones hidalgos que se enganchaban en los tercios de Italia para buscar lances de amor, de espada y de fortuna". ${ }^{7}$

Valle Inclán fue un escritor muy productivo; poco después de la publicación de las Sonatas incursionó de lleno en el teatro, género que siempre le apasionó y del que nos dejó más de veinticinco obras. En 1907 se estrena su primera obra dramática, basada en el protagonista de las Sonatas, El marqués de Bradomín, justo así titulada. Formaba parte del reparto de la obra la actriz Josefina Blanco, quien se casaría poco después con Valle Inclán, provocando, como era de esperarse, cierto escándalo en la mustia sociedad madrileña. Valle tenía 40 años y Josefina 28.

En 1910, ya casados, su mujer se incorpora a la compañía de teatro de García Ortega para realizar una gira por Sudamérica. Valle Inclán la acompaña en calidad de director artístico y tiene la oportunidad de dictar algunas conferencias sobre literatura española. La gira se extendió a varios países: Argentina, Chile, Paraguay, Uruguay y Bolivia. Tras seis meses de gira, ya reinstalado en Madrid, el escritor gallego continúa estrenando obras de teatro con mediano éxito. En 1916 es nombrado titular de la cátedra de Estética de las Bellas Artes de la Escuela de San Fernando, cargo en el que no permaneció mucho tiempo.

${ }^{6}$ Rubén Darío, en Ramón Gómez de la Serna, Don Ramón María del Valle Inclán, op. cit., p. 79.

${ }^{7}$ Emilio Diez Echarri y José Ma. Roca Franquesa, op. cit., p. 1371. 
Poco después de recuperarse de una intervención quirúrgica, se estrena Luces de bohemia (1920), considerada su mejor obra de teatro. Es la historia trágica de Max Estrella, poeta frustrado que se ha quedado ciego. Estrictamente, se habla de los dos últimos días de la vida de este personaje, hasta su muerte, que en la realidad corresponde al escritor Alejandro Sawa, amigo de Valle Inclán. La obra transcurre en Madrid y retrata la vida bohemia, literaria y política de la época. Entre los personajes secundarios aparece otro gran amigo de Valle, éste sí con nombre y apellido: Rubén Darío. La historia se convierte en una farsa grotesca; los escenarios donde se desarrolla la acción son sórdidos y sombríos: callejones, tabernas, cárceles, cementerios; los personajes, esperpénticos: borrachos, prostitutas, miserables.

En este drama Valle Inclán expone por primera vez su teoría del esperpento. En una de las escenas más relevantes, la voz de Valle en boca del protagonista Max Estrella, hace las famosas afirmaciones de que "España es una deformación grotesca de la civilización europea", y que, por lo tanto, "el sentido trágico de la vida española sólo puede darse con una estética sistemáticamente deformada", ${ }^{8}$ deformación que Max Estrella compara con la imagen de los héroes clásicos reflejados en los espejos cóncavos del madrileño Callejón del Gato. Esta distorsión produce el "esperpento". 9

La teoría del esperpento resulta de una paradoja, en la que se aplica un procedimiento deformador, con objeto de captar una realidad de la que, se nos dice, ya está deformada. Podría pensarse que esta teoría esperpéntica sólo se manifiesta en dos o tres obras de Valle a partir de Luces de bohemia; sin embargo, aparece esbozada ya

${ }^{8}$ Cfr. Luces de bohemia, 1962, Madrid, Aguilar, Obras Completas, escena XII, p. 173.

${ }^{9}$ Según ciertos comentaristas, "el esperpento valleinclanesco parte de un famoso bar madrileño el 'Callejón del Gato', situado muy cerca de la Plaza del Sol. Valle Inclán era un gran asiduo al mismo, en cuya fachada se hallaban unos espejos cóncavos y otros convexos, que deformaban la figura de todo aquel que pasaba frente a ellos. Esto que se convirtió en un entretenimiento de los madrileños de la época, sería utilizado por Valle Inclán como inspiración. La deformación de la realidad bien podía ser divertida, como de hecho lo era para los transeúntes, pero podía convertirse en algo más: un espejo social, una crítica, una deformación de la realidad exagerada”, Manuel Alberca, Valle Inclán, la fiebre del estilo, 2002, Madrid, Espasa Calpe, p. 52. 
en buena parte de sus obras anteriores. Según el escritor gallego, nuestra visión normal de la realidad ya está deformada o, en su caso, nos negamos a ver a las personas y a las cosas tal como realmente son. Así, el propósito de Valle Inclán es obligarnos a fijar la mirada en la superficie de las cosas y cerrar todos los caminos por los que pudiéramos escaparnos hacia una comprensión disculpadora. Para justificar la necesidad de gran parte de la conducta humana, necesitamos un sentido de profundidad espiritual. La respuesta de Valle Inclán es convertir a los hombres en marionetas, máscaras, monstruos, eliminando así la otra dimensión en la que se produce la ficción. La pregunta que surge es: ¿los esperpentos son lo que parecen ser, o parecen ser lo que son?

Efectivamente, Valle Inclán hace una fusión entre verdad y ficción. No hay sólo espejos cóncavos, sino verdades desnudas y a veces la verdad es más cruel que la deformación. En su conjunto, Luces de bohemia expresa toda la tremenda indignación del autor ante la situación política y social española, lo que lo acerca a sus compañeros de generación. Como el hijo pródigo, regresa a la casa paterna, a la España desgarrada y doliente, y alza la voz a su manera, con ese estilo propio e inimitable, irónico, insolente y caricaturesco. En esta obra, como en otras de su autoría, Valle Inclán aporta aciertos geniales, no sólo por su estética esperpéntica, sino por el manejo de la estructura, casi cinematográfica; por el dominio de la lengua castellana; por la riqueza y originalidad de su vocabulario, por el tono abrumador y rítmico, y en general por su natural elocuencia y creativa vitalidad.

La trascendencia de Valle Inclán en esta etapa de su quehacer literario (1920-1930) ha sido tan grande que en el mismo diccionario de la Real Academia Española se define, entre otros significados del término esperpento, como “estilo literario creado por Ramón María del Valle Inclán, que se caracteriza por la deformación grotesca de la realidad, al servicio de una implícita intención crítica de la sociedad". ${ }^{10}$

El esperpento más que un estilo literario, es una forma de ver el mundo, aún más, es una poética, es decir, una manera de crear; que consiste en retratar situaciones y personajes de una forma peculiar:

${ }^{10}$ Diccionario de la lengua española, Real Academia Española, 200122, Madrid, p. 109. 
degradados, reducidos a títeres, grotescos, paródicos y deshumanizados. Además de Luces de bohemia, máxima expresión del esperpento, pertenecen a este género teatral, la trilogía Martes de Carnaval, que incluye La hija del capitán, Las galas del difunto y Los cuernos de don Friolera.

Valle Inclán estuvo en México en dos ocasiones; la primera en 1892, desembarcado en Veracruz permaneció en el puerto por espacio de dos meses y, posteriormente, se estableció en la ciudad de México, donde permaneció cerca de un año. Durante su estancia en nuestro país colaboró en varios periódicos: El veracruzano independiente, El Universal y El Correo Español. Gobernaba en México Porfirio Díaz, la personalidad del dictador le impresionó, así como la situación política nacional. Valle Inclán, rebelde e insolente como era, protagonizó varios incidentes, entre otros, una escandalosa pelea en Veracruz y un amago de duelo en la ciudad de México con el redactor del periódico El Tiempo. De México se trasladó a Cuba y permaneció en la isla poco más de un mes.

En 1921 realizó un segundo viaje a nuestro país, invitado por el presidente de la República, el general Álvaro Obregón, por mediación de Alfonso Reyes, para participar en la celebración del primer centenario de la Independencia de México. Su recibimiento fue colosal, rindiéndosele grandes honores. Durante su estancia en la capital se alojó en el Hotel Regis y fue protagonista de numerosos actos culturales; hizo algunos viajes al interior de la República y participó en eventos organizados por la colonia española; seis meses permaneció en México y de regreso a España hizo escala en Nueva York por un par de semanas.

Sin duda su estancia en México y Cuba, y antes en países sudamericanos durante su gira teatral, le proporcionaron un amplio conocimiento de la vida política y social de Hispanoamérica, información y vivencias que le darían suficiente material para otra de sus obras más importantes, la novela Tirano Banderas, publicada en 1926.

Escrita cuando Valle Inclán contaba ya 60 años de edad y había experimentado con todos los géneros literarios, concibe esta novela de 
gran perfección literaria, probablemente la obra cumbre de su narrativa. Tirano Banderas, subtitulada Novela de Tierra Caliente, nos narra la caída del dictador hispanoamericano Santos Banderas, presidente de la República de Santa Fe de Tierra Firme, territorio imaginario descrito como una colonia española, localizada en centro o Sudamérica, y habitada por españoles, criollos e indios. Bien podría tratarse de México, Perú, Cuba, Bolivia o cualquier otro país hispanoamericano. La acción se desarrolla en dos días.

Como el título de la novela ya lo indica, se trata de una crítica mordaz y despiadada a la dictadura militar, a la tiranía y el caudillismo, no sólo hispanoamericano sino de cualquier región del planeta. En ella se funde lo ambiental, el retrato de los personajes, mediante unas cuantas pinceladas exactas, la crónica novelesca y la novela de acción. La obra está dividida en siete partes, un prólogo y un epílogo. Utiliza la técnica de acciones y descripciones sintéticas, rápidas, cortantes, que se precipitan hacia un final previsible, pero sorprendente por lo explosivo y dramático. La estructura es, pues, perfecta; podría ser por su formato una obra clásica: no en vano Valle Inclán era un profundo conocedor de la literatura universal.

Los personajes son, en su mayoría, verdaderos esperpentos: el protagonista Santos Banderas, general de la República, es cruel y despiadado, un monstruo sin sentimientos cegado por el poder, que al final de la novela mata de quince puñaladas a Manolita, su propia hija de 20 años, con retraso mental, para que no fuera violada por sus enemigos. Otro personaje espeluznante es el ministro de su Majestad Don Mariano Isabel Cristino Queralt, Barón de Benicarlés, un viejo español homosexual, que mantiene relaciones con un bailarín llamado "Currito Mi-Alma". No menos desagradable es Quintín Pereda, prestamista, usurero inmisericorde, que se enriquece estafando a las gentes sin recursos. Lo grotesco y ridículo de muchos de estos personajes nos provoca la carcajada, pero también el desprecio y la aversión. Su crítica más severa es hacia los peninsulares, clérigos y militares; con los revolucionarios es menos despiadado, pero no dejan de ser títeres y caricaturas en muchos aspectos. 
Esta crítica satírica - a veces demoledora- no sólo es política, se extiende a lo social, a lo cultural, a lo religioso. Como en un documental cinematográfico, se suceden una tras otra escenas impactantes, mórbidas, groseras, sin ninguna explicación de por medio. Mención especial merece el magistral dominio del lenguaje, ya característico en las obras de Valle Inclán; pero en esta novela introduce, además, un riquísimo vocabulario, propio del castellano hablado en Hispanoamérica, mezclado con innumerables dialectismos y palabras llenas de colores, olores, sabores y ritmos sureños que contribuyen a destacar el ambiente paródico y esperpéntico de la historia.

Independientemente de su valor literario, Tirano Banderas se convierte en la obra precursora de la novela del dictador, considerada ya como subgénero narrativo, característico de la literatura hispanoamericana contemporánea. Quizá sólo le antecede Don Facundo, del argentino Domingo Faustino Sarmiento, publicada en 1845. Como sabemos, casi todos los países hispanoamericanos han sufrido -algunos aún lo sufrendictaduras de uno u otro signo a lo largo de su historia. Regímenes totalitarios, de tipo caudillista, en los que un individuo asume todos los poderes y personifica al Estado. No es de extrañar, por ello, que naciera este género narrativo precisamente así, novela del dictador.

Aunque el auge de este tipo de novelas se produce mayormente en los años setentas, con el boom de la novela hispanoamericana, sus orígenes son mucho más antiguos, y Tirano Banderas se convierte en cabeza de serie para este tipo de novelas de crítica a las dictaduras y tiranías. Desde luego, ninguna de las novelas que se han escrito en esta línea son iguales; cada una de ellas enfatiza, profundiza o recrea diferentes aspectos de la dictadura, amén de los estilos propios de cada autor. Después de Tirano Banderas, publicada en 1926, entre las novelas más conocidas de este género figuran: La sombra del caudillo (1929), de Martín Luis Guzmán; El Señor Presidente (1946), de Miguel Ángel Asturias; Maten al león (1969), de Jorge Ibargüengoitia; El recurso del método (1974), de Alejo Carpentier; Yo el Supremo (1974), de Roa Bastos; El otoño del Patriarca (1975), de Gabriel García Márquez y La fiesta del chivo (2000), de Mario Vargas Llosa. 
Probablemente, la más cercana de estas novelas a Tirano Banderas, es la del mexicano Jorge Ibargüengoitia, Maten al león; en ambas, el dictador en cuestión no es un personaje histórico, el país donde se desarrollan los hechos es ficticio, por lo que permite a los autores mezclar costumbres, modismos y características geográficas de diversos lugares de Hispanoamérica. Por otra parte, la situación histórica, política, etc., no se analiza a profundidad, se enfatiza más la crítica personal al dictador; en el caso de la obra de Ibargüengoitia, con un humorismo paródico, genial, sin rencores ni sordidez; en el caso de Valle Inclán, con una mordacidad despiadada y cruel. En Maten al león se narra una deliciosa farsa, donde los héroes son tan ridículos como sus enemigos; en Tirano Banderas, casi todos los personajes son monstruosos, deleznables, esperpénticos.

Después de Tirano Banderas, el escritor gallego publicó la obra El ruedo ibérico (1927-1928), que incluye una serie de novelas cortas, también esperpénticas. Asimismo, poco después estrenó una magnífica obra de teatro titulada Martes de carnaval (1930), igualmente en la línea esperpéntica. Valle Inclán, como ya se ha señalado, fue un escritor muy prolífico, se conocen más de 60 obras de su autoría, sin contar artículos periodísticos y traducciones del francés e italiano, pero muchas de ellas no tienen la calidad literaria de las que se han mencionado: "Acaso haya despilfarrado mucho de su talento y algo de inspiración en la riesgosa aventura de crearse una biografía espectacular, restándole sustancia a su producción literaria". ${ }^{11}$

Efectivamente, Valle Inclán llevó una vida muy azarosa y llena de escándalos; uno de los más estrepitosos fue el pleito que protagonizó en 1899 en el Café de la Montaña con el periodista Manuel Bueno, quien de un bastonazo le ocasionó tal herida que se gangrenó y hubo que amputarle el brazo. Desde entonces, la imagen del escritor manco se empezó a mitificar. No faltaron otros pleitos que lo llevaron a parar tras las rejas, como el ocurrido en el Palacio de la Música: por no pagar una multa, fue encerrado en la cárcel Modelo de Madrid. A los juzgados se presentó en varias ocasiones acusado de no pagar la renta e insultar al casero en turno. Incursionó en la política en el bando republicano,

${ }^{11}$ Armando Urbideti, op. cit., p. 30. 
aunque no llegó a ser elegido diputado. En 1932, el gobierno de la República lo nombró director del Patrimonio Artístico Nacional y después del Museo de Aranjuez; en ambos casos dimitió por desavenencias con sus superiores. Ese mismo año se divorció de su esposa, la actriz ya mencionada, Josefina Blanco. Tuvo pleitos por la custodia de los hijos. En 1933 fue nombrado director de la Escuela de Bellas Artes de Roma, cargo en el que permaneció sólo un año. Su salud empezó a menguar. A muy pocos amigos permitía visitarlo, Miguel de Unamuno y Ramón Gómez de la Serna, entre otros. En 1935 se retiró a Santiago de Compostela, donde fue hospitalizado. El 5 de enero de 1936, víspera de Reyes, tras negarse a recibir auxilio religioso, el "eximio escritor y extravagante ciudadano" muere a los 69 años de edad.

Digno sucesor de Quevedo, Lope y Cervantes, Valle Inclán tuvo la heroica insolencia que eleva al artista por encima de la masa espesa y municipal (como llamara su amigo Rubén Darío al vasto sector de la población que vive en el conformismo y la ignorancia), pues nunca aceptó transigir con las injustas demandas de una sociedad vulgar y mezquina; prefirió la pobreza, el desprecio y la incomprensión antes que pactar con los emisarios del orden establecido a quienes puso en evidencia mediante su admirable facultad satírica, misma que le permitió fustigar sus propias debilidades en un caso ejemplar de autocrítica. Solo así puede entenderse que haya calificado a gran parte de su obra como musiquilla de violin. ${ }^{12}$

Hombre violento, teatral, estrafalario y profundamente orgulloso, Valle Inclán hizo de su persona un símbolo de la impasible altivez aristocrática; no obstante, dejaba entrever bajo su excéntrica apariencia la timidez de quien se siente solo e indefenso frente a un mundo hostil. Sin embargo, las repetidas decepciones que padeció no lo debilitaron, puesto que supo aprovecharse de ellas con reconcentrada energía, transformándolas en sublimes motivos poéticos y en grotescas caricaturizaciones o en espeluznantes esperpentos.

${ }^{12}$ Ibidem, p. 33. 
Valle Inclán dejó para la posteridad una obra saturada de contradicciones y atisbos, desprovista de toda intención doctrinal -lo cual le agradecemos-, pero plena de sensibilidad que discurre con total libertad a través de fulgurantes imágenes y musicales sonoridades. Como la mayoría de los miembros de su generación, se adelantó a su tiempo y nos legó varias obras inmortales. El hijo pródigo encuentra su legítima voz en la voz de España, desde el Arcipreste de Hita hasta Quevedo y Larra. Con su estética del esperpento, llevó a la literatura el mismo espíritu con el que Goya revolucionó la pintura. 
La reproducción total o parcial de este artículo se podrá hacer si el ITAM otorga la autorización previamente por escrito. 